Proceedings of the 2011 Winter Simulation Conference

S. Jain, R.R. Creasey, J. Himmelspach, K.P. White, and M. Fu, eds.

\title{
A CONCEPTUAL COMPARISON BETWEEN DISCRETE AND CONTINUOUS SIMULATION TO MOTIVATE THE HYBRID SIMULATION METHODOLOGY
}

\author{
Thiago Barros Brito \\ Edson Felipe Capovilla Trevisan \\ University of Sao Paulo \\ Department of Logistics Systems Engineering \\ CILIP (Innovation Center for Logistics and Ports \\ Infrastructure) \\ Sao Paulo, BRAZIL
}

\author{
Rui Carlos Botter \\ University of Sao Paulo \\ Department of Naval Engineering \\ CILIP (Innovation Center for Logistics and Ports \\ Infrastructure) \\ Sao Paulo, BRAZIL
}

\begin{abstract}
The aim of this essay is to encourage the application of the hybrid simulation, combining the discrete and the continuous simulation methodologies. With a conceptual literature review of discrete (Discrete Event) and the continuous (System Dynamics) simulation methodologies that reveals their main features and potential of applicability, it is possible to define the potential of developing hybrid simulation models. The integration of both methodologies in a single model allows the expansion of the comprehension spectrum of the system, with the possibility of integrating the physical and dimensional aspects to policy and behavior patterns, revealing the hybrid methodology as a powerful tool to succeed in the highly demanding business world.
\end{abstract}

\section{INTRODUCTION}

The globalized and competitive scenario in which we live imposes the knowing and practicing of different knowledge, in constant search for the extraction of its best qualities. Only then it is possible to survive the managerial and competition demands of the modern society. Thus, the demand for hybrid elements is incited. Hybridism is the quality of everything that results from the combination of elements of different natures, and is present in the most diversified organizational fields - from cars (running on alcohol and gasoline) to ground coffee (combining the qualities of different types of seeds). The purpose of a hybrid element is to provide the user (consumer, programmer, etc.) the possibility of extracting the best (or more interesting) characteristics of each one of the combined elements.

In the computational simulation field, the term "hybrid simulation" refers to the combination of discrete and continuous simulation methodologies, represented in this paper by their main paradigm: the Discrete Event Simulation (DES) and the System Dynamics (SD). In the scientific community it is common to affirm the potentiality of both methodologies (DES and SD) to complement each other, offering the necessary tools to build new simulation paradigms, filling the requirements of the modern, integrated and demanding collaborative systems. However, the progress towards this direction is still limited.

Through a detailed study of the practical, theoretical and technical aspects of DES and SD, this study's purpose is to identify an environment of intercommunion between the two methodologies, strengthening the concept of the hybrid simulation methodology. The identification of the strong and weak points of each methodology allows a deep comparison of both, identifying their respective possibilities of application and contribution towards a common direction. 


\section{LITERATURE REVIEW}

The discrete and continuous simulation will be represented in this paper through the two main traditional methodologies of modeling and simulation: the Discrete-Event Simulation (DES) and the System Dynamics (SD). DES and SD have been traditionally applied to particular situations, aiming at the extraction of the main benefit offered by each of the methodologies and considering their applicability limitations, situation that will be discussed further in this study. However, both have achieved success in the modeling and simulation of logistics systems, the area of focus for this effort. There are a considerable number of specialists who, used to success in the application of their "favorite paradigm", don't even consider the possibilities presented by the other paradigm.

DES's approach corresponds to the vision of entities' flow. Law and Kelton (2000) define a DES system as a collection of entities that act and interact together through flows in the system, aiming at a logic closure. For the purpose of this investigation, DES models are composed by a network of activities, resources and queues, through which the entities flow with state changes occurring at discrete points of time, through the so called "events." Entities, activities, resources, queues and events are, thus, the main elements of a DES model (Helal 2008). The integration of elements of the DES methodology is made through a calendar of events.

Traditionally, DES has been efficiently applied to simulate complex logistics systems. It is able to replicate accurately the behavior of any system, providing the decision-maker with valuable information about how the system may perform and how it can be modified (Sweetser 1999). However, the traditional application of the DES has focused on the aim of its employment to statistical analysis, keeping it restricted to the operational level of the system.

One of the most worrying limitations of DES is that it is not capable of addressing the stability of the system (Rabelo et al. 2005), an important matter to be considered in a more aggregated level of planning, before any analysis or strategic decision of the system is taken (Towill and Edghill, 1989). The stability which is referred to is based on the concept of BIBO-stability (bounded input-bounded output). According to this concept, a system is said to be stable if, to every limited amplitude signal applied to its input, the output signal is also limited.

The most extensive definition of SD is from Sterman (2000), that describes SD as a methodology able to improve the comprehension of complex systems, by capturing and presenting to the user causal diagrams, loops of feedback and flow, and the interaction and lag mechanism between the components of the system (Tesfamariam and Lindeberg, 2005). SD offers an approach that takes an integrative perspective of the system and its main characteristic is the recognition of inherent processes of feedback in the structure of modeled systems (Helal 2008). Forrester (1961) defines SD as a "study of the characteristics of the feedback of information ... to show how the organizational infrastructure, policies and lags (in decision processes and actions) interact to affect the success of the enterprise".

Then, it is natural that the fundamental structure of SD is the relation between its components. The clear perception of the interrelation between the components (that might be people, organizations, processes, resources, etc.), created through the structures of causal diagrams and loops of flow and feedback, allows the evaluation of the system's performance.

\section{CONCEPTUAL COMPARISON OF DES AND SD}

The study of Borshchev and Filippov (2004), takes into account the segregation of the study field and the application of both simulation paradigms, and evaluates the extension of the logistics problems that are efficiently addressed with simulation models constructed under the two paradigms (Figure 1).

The typical approach of the highest level of the Figure 1 is based on the consideration and evaluation of aggregated values, global feedbacks of the system, tendencies and policies of decision making. Individual elements are rarely considered. The high aggregation level becomes "naturally" appropriate for the SD paradigm. Meanwhile, the approach in the last level is typical of the "physical modeling," where the 
individual objects, punctual processes of decision, distances, times, etc., are considered (Borshchev and Filippov 2004). In this case, DES is the more suitable paradigm.

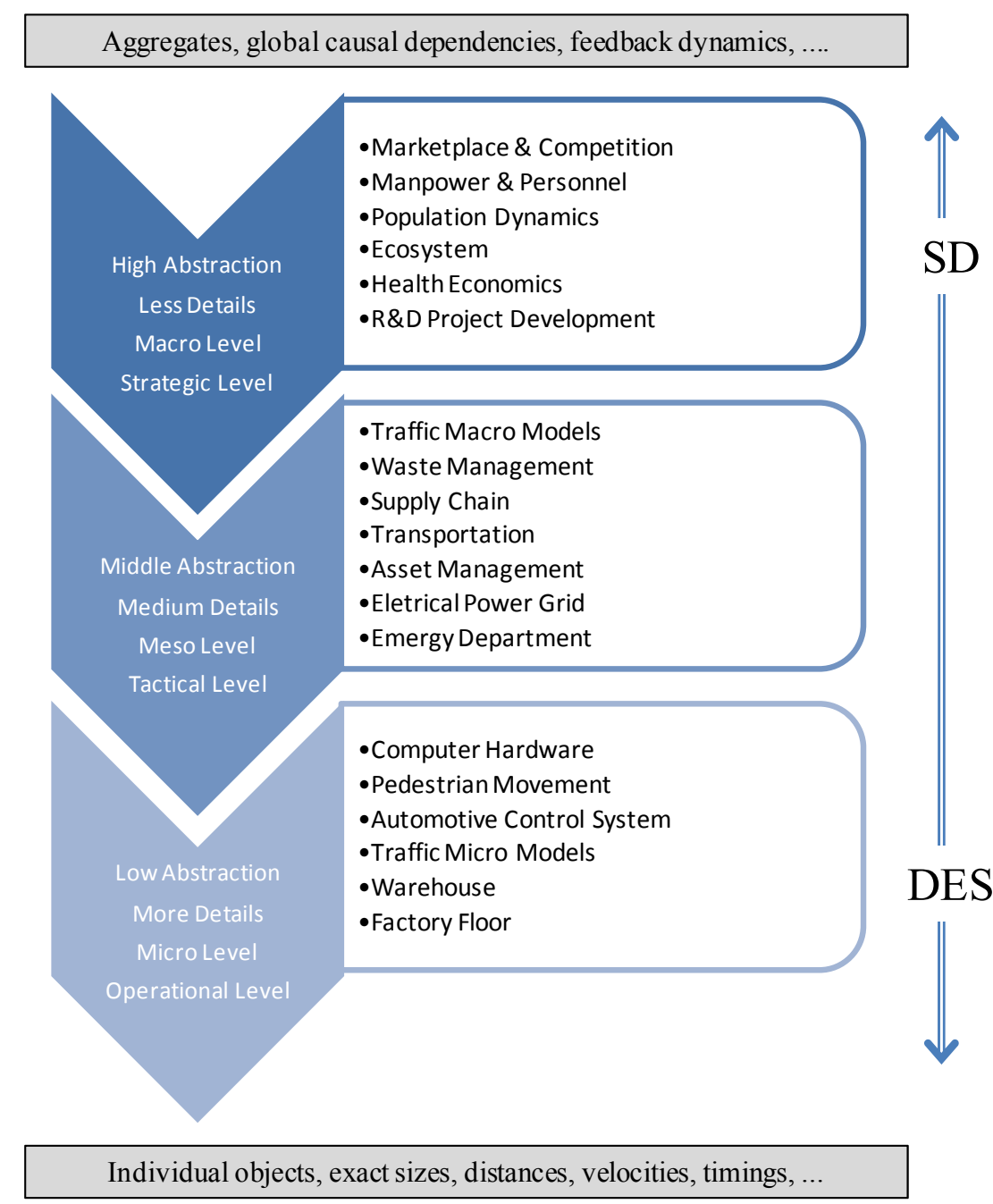

Figure 1: Examples of applications of the simulation methodologies organized relatively to the scale of necessary abstraction for the construction of the model (based on Borshchev and Filippov (2004))

Through an observation of the application of both methodologies, it is possible to primarily conclude that the DES generally presents potentialities that make it more suitable to simulate systems with low level of abstraction and more details or specific and well defined processes (Sweetser 1999). SD, on the other hand, is more suitable to simulate continuous processes related to extensive processes of feedback. Such affirmations are made based in the classic considerations found in studies and textbooks about the DES and SD paradigms. A more detailed explanation about both methodologies will be presented in the next item, which may encourage reconsidering the applicability of both methodologies.

The existent literature about the comparison of the two approaches of simulation is scarce. The studies about the comparison of DES and SD consist mainly of commonly accepted affirmations in the field of Operational Research (Brailsford and Hilton, 2001; Morecroft and Robinson, 2005) and tend to present a vision directed to one of the approaches, depending on the professional or academic experience of the author. The mentioned commonly accepted affirmations are resumed and presented in the study of Sweetser (1999): 
- DES models present potentialities (related to its technical and practical aspects) that make it more suitable for the detailed analysis of specific and well defined systems or linear systems

- SD methodology is suitable to the modeling of continuous processes, in which the behavior changes in a non-linear manner or extensive loops of feedback

Coyle (1985) and Lin at al. (1998) also affirm that DES models work well with problems of limited scope, but are incompatible with models of global perspectives, because of its difficulty in dealing with the stability of the system. Alternatively, the application of the SD methodology has been constantly successful as an approach of systems thinking, aiming at an integrative perspective in an elevated managerial level (Helal et al. 2007). In the practical view, SD is generally used in problems such as the analysis of policy strategies, incorporating aspects of the soft behavior of the system that, while difficult to quantify, may affect significantly the performance of the system (Sweetser 1999). Table 1 summarizes the main differences spotted between the two approaches.

Table 1: Conceptual and technical differences between the methodologies SD and DES (Mak (1993, 228), Lane (2000), Brailsford and Hilton (2001))

\begin{tabular}{lll}
\hline \multicolumn{1}{c}{ Aspect } & \multicolumn{1}{c}{ DES } & \multicolumn{1}{c}{ SD } \\
\hline Perspective & Analytic, emphasis on detail complexity & Holistic, emphasis on dynamics complexity \\
\hline Model Nature & Stochastic & Deterministic \\
\hline System Building Configuration & Network of queues and activities & Series of stocks and flows \\
\hline Resolution & $\begin{array}{l}\text { Individual entities, attributes, decision and } \\
\text { events }\end{array}$ & $\begin{array}{l}\text { Homogenized entities, continuous policy } \\
\text { pressures }\end{array}$ \\
\hline State Change & At discrete points of time; Event-stepped & "Continuous"; Finely-sliced time-stepped \\
\hline Data & Numerical with some judgmental elements & Broadly drawn \\
\hline Problem Scope & Operational & Strategic \\
\hline User Perception & Opaque box & $\begin{array}{l}\text { Transparent Box } \\
\text { Outputs }\end{array}$ \\
\hline
\end{tabular}

Tako and Robinson (2009a) also provide a table comparing the paradigms DES and SD with a focus on the dynamic between the user and the methodology (presented as Table 2).

Based on the comparative tables (Table 1 and Table 2) and the study of Morecroft and Robinson (2005) that build two different models of the same system under the same conditions (one under the DES approach and the other under the SD approach), a final table of comparison between both methodologies is presented as Table 3, where the technical and conceptual differences are shown.

It is inferred, first, that SD is involved in the activity of understanding the performance of a system through time, and is dependent principally on the definition of its loops of feedback. The structures of feedback are made explicit through a series of equations that are frequently non-linear. Besides, the randomness is not usually thought of, and when considered, it is simplified or included in the structures of lags. The DES is also involved with the activity of understanding the performance of the modeled system, being mainly dependent on external and internal random processes, vital elements in the definition of the behavior of the system. The loops and feedbacks are not explicitly characterized in the model. Besides, the tendency of DES is to represent the relation between its elements through linear processes. 
Table 2: Summary of the comparison of the dynamics between SD and DES and the user (Tako and Robinson (2009) and Lane (2000))

\begin{tabular}{lll}
\hline \multicolumn{1}{c}{ Model Use } & \multicolumn{1}{c}{ DES } & \multicolumn{1}{c}{ SD } \\
\hline Understanding & $\begin{array}{l}\text { User does not understand the } \\
\text { underlying mechanics }\end{array}$ & Model is transparent to the user \\
\hline Validity (Credibility) & \multicolumn{1}{c}{$\begin{array}{c}\text { Both models are perceived and representative, provide realistic outputs and } \\
\text { create confidence in decision-making }\end{array}$} \\
\hline Usefulness & $\begin{array}{l}\text { Less used as learning tool; good } \\
\text { communication tool }\end{array}$ & $\begin{array}{l}\text { So-called "learning laboratories"; good } \\
\text { communication tool }\end{array}$ \\
\hline Results & $\begin{array}{l}\text { Stastistically valid estimates of } \\
\text { performance; interpretation requires } \\
\text { mathematical background }\end{array}$ & $\begin{array}{l}\text { Easily interpreted; little or no statistical } \\
\text { analysis is required }\end{array}$ \\
\hline
\end{tabular}

Table 3: Main differences between the approaches DES and SD (adapted from Morecroft and Robinson, 2005)

\begin{tabular}{|c|c|}
\hline Discrete-Event Simulation (DES) & System Dynamics (SD) \\
\hline \multicolumn{2}{|c|}{ Representations } \\
\hline $\begin{array}{c}\text { System represented as a network of activities, } \\
\text { resources and queues through which the entities } \\
\text { flow }\end{array}$ & $\begin{array}{c}\text { System represented as a diagram of stocks and } \\
\text { flows }\end{array}$ \\
\hline Feedback loops and stability not characterized & Explicit feedback loops \\
\hline Most relationships between elements is linear & A good chunk of the relationships between \\
elements is non-linear
\end{tabular}

It is possible to conclude that the SD approach has the construction and analysis of loops of feedbacks and the representation of the lags dynamics in the modeled systems as a vital element. The DES paradigm emphasizes the consideration of randomness of the involved processes in the model, as well as the linear relationship between the majority of its variables. This makes them conceptually different, making it necessary to incorporate the subtle differences and exigencies of each paradigm and their respective modeling processes.

Another outstanding and defining characteristic of the applicability of the methodologies is the level of aggregation. The SD works with a level of aggregation of the elements of the system known as "conceptual distance" (Lane 2000), and is positioned one step before the level of the events, which are softened inside standards of continuous behavior (flows and policies of decision). It is argued that the policy of decision and the dynamic behavior (and not the events and individual decisions) are connected through the elementary concept of feedback, which constitutes only the superficial layer of the decision policies 
(Richarson and Pugh 1981). If the "conceptual distance" is not adopted, the whole strength of the concept of feedback would be lost.

A consequence of the level of aggregation of the SD is the treatment of inserted and extracted data from the model. SD models deal with general data and numerical extrapolations, without bigger preoccupations with precision, which allows the inclusion of the least tangible variables in the model (known as soft variables) that can fulfill important role in the understanding of the behavior of the system.

The conceptual differences between the methodologies are meanwhile responsible for the creation of environments and situations favorable to the applicability of each one of them. The application of the DES, almost absolutely, refers to the modeling of logistics systems under the operational scope, through the characterization of processes, events, individual decision making and numerical formalism. The application of SD, on the other hand, refers to the modeling of logistics systems under the strategic scope, through the formalization of the relations between the major planning variables of the system and policies of decision making. One falls back on the previously discussed "commonly accepted" comparison in the scientific community, now being supported by a theoretical referential.

\section{CONCLUSIONS ABOUT THE DES AND SD COMPARISON}

The final evaluation about the comparison between the SD and DES methodologies will be executed through the construction of 3 comparison models, schematized in Figure 2. The comparison models are a rereading and a revamp of the work of Lane (2000), which makes a comparison between discrete and continuous simulations.

1. Concentrating in the theoretical and practical differences between the two and in the difficulty of communication between the specialists. The final conclusion is of that the approaches are absolutely different methodologies, whose application and development must be absolutely independent.

2. Concentrating in their similarities and working on the concept of that, in depth, DES and SD represent essentially the aspects of one single methodology.

3. Through an effort for a deeper understatement of DES and SD, based on the literature review and definitions presented so far, which allows the searching for opportunities for the creation of areas of application and common efforts of development, but remaining conscious of its differences and particular applications.
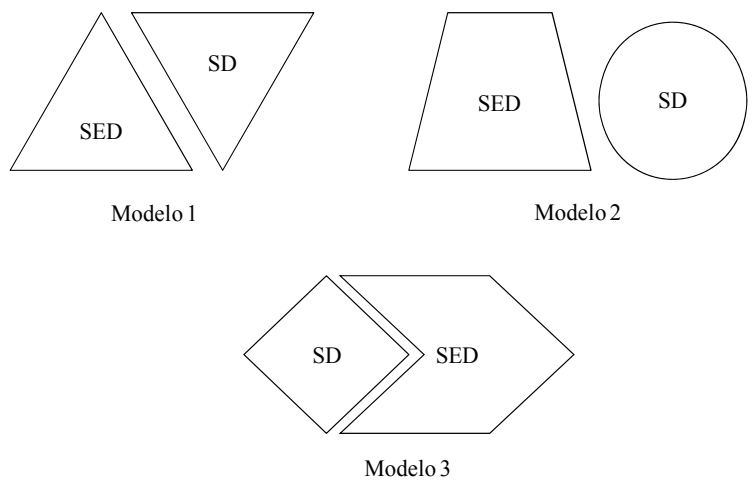

Figure 2: Representation of the three models of comparison between the methodologies

The model 3 of comparison brings in its essence the final objective of the work: the development of the methodology of hybrid simulation (discrete + continuous), while the models 1 and 2 of comparison represent the current state of the simulation, regarding the integration between two methodologies. 


\subsubsection{Model 1}

The model 1 proposed is supported by the affirmation of the differences between the aspirations, hypotheses and methods of understanding and representation of the world of the two simulation methodologies. From the considerations and literature review, 8 criteria of comparison were selected, allowing a visualization of the fields of application, objectives and common or uncommon characteristics of two methodologies. The criteria of comparison selected are presented in Figure 3 as dimensions of a radar-graphic, according to the structure proposed by Randers (1980).

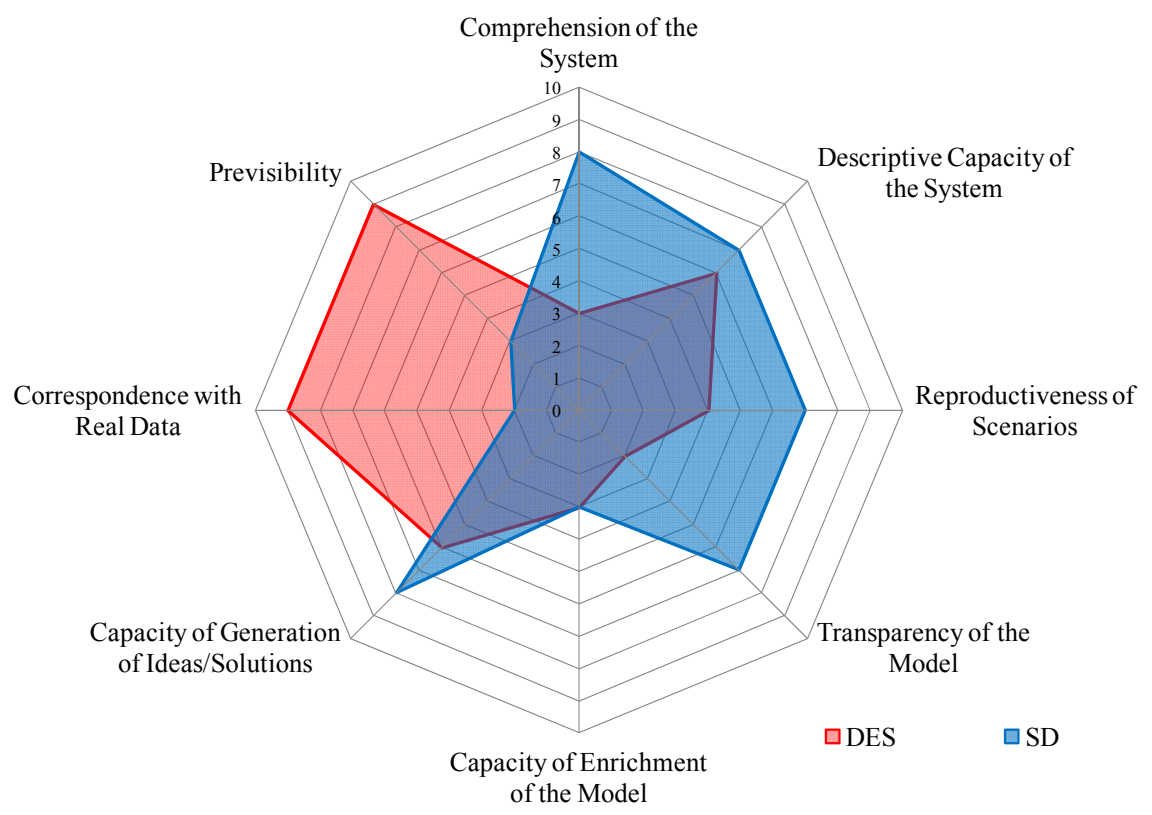

Figure 3: Comparison of the characteristics of DES and SD methodologies (adapted from Lane (2000))

The judgments were carried out based in the understanding of the application and characteristics of both methodologies by the author, on a scale from 0 to 10, and are presented in Table 4.

Figure 3 shows the clear perception of how, even with common characteristics between the two methodologies, they cover distinct areas, supporting the comparison model 1 . The considerations in the Table 4 highlight essential differences in the elements and characteristics of DES and SD, visualized in Figure 4.

The result of this speech is the conceptual and practical removal, discouraging the communication and the communion between them.

\subsubsection{Model 2}

The model 2 concentrates on the similarities between DES and SD. The model proposes and assumes secondary differences in the approaches, but the argument is that both represent one single methodology.

The basic definition of the acting field of the two paradigms and of the final objective of any simulation methodology is a strong argument for the comparison model 2: "Fundamentally, a model of simulation "-----" offers a powerful tool of analysis that allows the logical, free of risks and flexible experimentation of a system of the real world. It is able to produce an understanding of the real system and to predict its behavior according to the interest of the modeler" (Lane,2000). The passage marked with "----", might be occupied, in an equally suitable way, either by the term SD or DES, which represents a strong indication of a common field of acting of DES and SD. 
Table 4: Evaluation of the 8 comparison criteria of the SD and DES methodologies

\begin{tabular}{|c|c|c|c|c|}
\hline Dimension of Comparison & Definition & SD & SED & Coments \\
\hline $\begin{array}{l}\text { Comprehension of the } \\
\text { System }\end{array}$ & $\begin{array}{l}\text { Methodology's capacity of expanding } \\
\text { the comprehension of the system } \\
\text { modeled by the user. }\end{array}$ & 8 & 3 & $\begin{array}{l}\text { The approach proposed by SD, which involves setting up of } \\
\text { feedback loops and emphasizes the relationship between the } \\
\text { system components, offers a large advantage compared to } \\
\text { the DES methodology. }\end{array}$ \\
\hline $\begin{array}{l}\text { Descriptive Capacity of the } \\
\text { System }\end{array}$ & $\begin{array}{l}\text { Corresponds to the extension with } \\
\text { which the elements of the model } \\
\text { manage to represent the real world. }\end{array}$ & 7 & 6 & $\begin{array}{l}\text { Following the line above, a SD model, built with the proper } \\
\text { precautionscan actually represents the behavior of the real } \\
\text { world better, or at least as well as a DES model. }\end{array}$ \\
\hline $\begin{array}{l}\text { Reproductiveness of } \\
\text { Scenarios }\end{array}$ & $\begin{array}{l}\text { Capacity of the methodology in } \\
\text { producing a set of scenarios and } \\
\text { behaviors of the model. }\end{array}$ & 7 & 4 & $\begin{array}{l}\text { The SD aggregate treatment, which deals with general } \\
\text { policies for decision making, allows the exploration } \\
\text { of a wider range of scenarios, but that loses ground in the } \\
\text { sensitivity analysis process of scenarios to DES models. }\end{array}$ \\
\hline Transparency of the Model & $\begin{array}{l}\text { It refers not to the validity of a model, } \\
\text { but to its structural-logically } \\
\text { transparency to the user. }\end{array}$ & 7 & 2 & $\begin{array}{l}\text { The concept of transparent-box present in the development of } \\
\text { SD models provides a significant advantage towards the } \\
\text { concept of black box of DES models. }\end{array}$ \\
\hline $\begin{array}{l}\text { Capacity of Enrichment of the } \\
\text { Model }\end{array}$ & $\begin{array}{l}\text { It aspires to the measure of the } \\
\text { easiness of a model in being } \\
\text { expanded or remodeled. }\end{array}$ & 3 & 3 & $\begin{array}{l}\text { Both methodologies offer a high level of re-work for the } \\
\text { remodeling of logics previously built. }\end{array}$ \\
\hline $\begin{array}{l}\text { Capacity of Generation of } \\
\text { Ideas/Solutions }\end{array}$ & $\begin{array}{l}\text { Corresponds to the fertility of the } \\
\text { methodology in the generation of } \\
\text { intuition or relevant perceptions to the } \\
\text { solution of the proposed problem. }\end{array}$ & 8 & 6 & $\begin{array}{l}\text { The SD, while dealing with policy management decision- } \\
\text { making rather than discrete decisions, creates a greater } \\
\text { potential in developing action plans for the system as a whole. }\end{array}$ \\
\hline $\begin{array}{l}\text { Correspondence with Real } \\
\text { Data }\end{array}$ & $\begin{array}{l}\text { It reports the capacity of the model in } \\
\text { representing the historical data with } \\
\text { signification. }\end{array}$ & 2 & 9 & $\begin{array}{l}\text { Data and events aggregation to build the SD model } \\
\text { represents a significantly lower accuracy in both input and } \\
\text { output data in comparison to DES models. }\end{array}$ \\
\hline Previsibility & $\begin{array}{l}\text { Capacity and precision of the model in } \\
\text { predicting future events and its effects. }\end{array}$ & 3 & 9 & $\begin{array}{l}\text { For similar reasons to those outlined above, but even more } \\
\text { emphatically, DES models takes advantage of SD models. }\end{array}$ \\
\hline & DES & \multirow{6}{*}{$\mathbf{X}$} & & SD \\
\hline & •flow of entities & & $\bullet$ fe & edback and causal loops \\
\hline & -linear relationships & & & -aggregation \\
\hline & •individual events & & & -politic of decision \\
\hline & -black-box & & & -opaque-box \\
\hline & -randomness & & & $\bullet \operatorname{lags}$ \\
\hline
\end{tabular}

Figure 4: Summary of the conceptual differences between DES and SD paradigms

Still, two of the main aspects pointed out as key differences between the two methodologies, can be re-visited and re-evaluated:

- Aggregation x Events: The SD works in an elevated level of aggregation, in an approach oriented to the definition of general policies of decision making and homogeneous flows, at the so called "conceptual distance" to events and individual decisions, which correspond to the defining elements of the behavior in DES models. Meantime it is possible to affirm that SD considers the individual events in the process of modeling (Graham 1980) at two different stages: the construction of the model and the analysis of its results.

- Range of application: One of the "commonly accepted affirmations" in the comparison of two methodologies of simulation refers to the range of application of DES and SD. The range of application of SD is defined by its main elements - the loops of feedback and the "conceptual distance" of individual events. The structures of feedback, that treats the determination of the causal relations between the variables of the model and are made explicit through a series of frequently non-linear equations, are able to incorporate "soft" aspects of its behavior, besides incorporating 
the question of the stability of the system. Associated to that, the level of aggregation provided by the "conceptual distance" supplies a global perspective of the system in study. As for DES, it operates well with problems of limited scope (Lin at al. 1998), and is incompatible with models of global perspectives, because of its difficulty in dealing with the stability of the system, as it does not consider the feedback processes of the system.

However, a more critical analysis confirms that the loops of feedback are considered in the DES models: while the SD programmers invest considerably more time in the stage of conceptual modeling that wraps the identification of the relationships between the parameters of the model, the DES programmers carry out these considerations not explicitly (Sweetser 1999, Lane 2000, Morecroft and Robinson 2005), but inside the stage of codification of the model itself (stage in which they usually spend more time in). To exemplify, the left part of Figure 5 presents the codification of a simple DES model, corresponding to the arrival and discharge of a ship in a port terminal, identifying the loops of feedback and the relations between variables. The implicit construction of a corresponding loop of feedback in the SD model is explicitly identified in the right part of Figure 5, between variables of "Unload Rate" and "Level of Remaining Cargo."

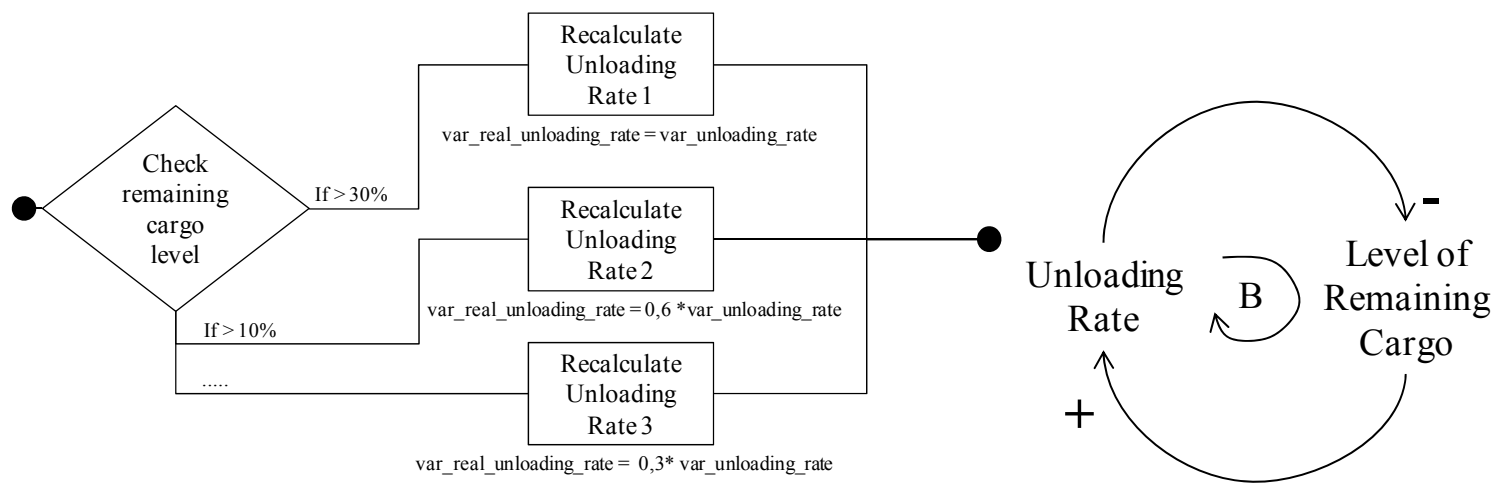

Figure 5: Details of the relation between variables in a DES model

The re-visit to two of the points and the considerations presented about the comparison between the two methodologies point to the direction that each one of the methodologies represent aspects and nuances of one single methodology.

\subsubsection{Model 3}

The proposal of a third model of comparison between the methodologies, first raised by Lane (2000), aims at obtaining a balance between the models of comparison, with the main purpose of preparing ground so that the DES and SD users can visualize the existent potential in the integration of the two methodologies.

The first point to be taken into account is that the propositions of the two models, if not taken extremely, are correct. So, it is possible to affirm that the DES and SD methodologies present unique characteristics, they have exclusive concepts and behave particularly well in specific situations, but they are, at the same time, similar in many aspects. Both have obtained success in logistics systems model building and the credibility of both cannot be denied; the models built by both paradigms are able to represent closely the behavior and performance of any system, providing to the decision maker the potentiality of evaluating all possible configurations and any modifications at the system.; the stages involved in the modeling process of both methodologies are equivalent and they present interactive and iterative characteristic.

Another point that reflects the similarity between the methodologies is the non-significant perception of the "lay" user regarding the results and application of the DES and SD methodologies (Tako and Rob- 


\section{Brito, Botter, and Trevisan}

inson, 2009b). This can imply that, from the point of view of the user, the applied methodology has little or no difference. Akkermans (1995) also affirms that the client is not worried about the choice of the approach of simulation, but only with the result presented by this application. So, the choice of the paradigm is not a critical factor for the user, it is enough that its application is successful.

The literature review revealed that there is a general level of agreement between the authors according to the differences between the methodologies of simulation. These conceptual and practical differences can be summarized in one single aspect: to deliver distinct possibilities of "vision of world", being the programmer responsible for the most suitable choice for its necessities. The "vision of world" of both methodologies can be explained through the three-dimensional graphic in Figure 6 proposed by Lane (2000), which positions the DES and SD methodologies regarding the complexity level (dynamic, combinatory and organizational) of application in which the models are able to work with unquestionable efficiency.

- combinatory complexity: refers to the complexity found in the search for the optimal solution amidst a great number of options.

- dynamic or structural complexity: is originated by the network of interactions between the elements of a system.

- Organizational complexity: refers to the complexity in the context of the understanding of the problem and its definition, which may vary in accordance to the values present inside the group of decision makers and to the human interactions. Jackson and Keys (1984) affirm that the measure of the organizational complexity captures the idea that some problems cannot be represented without causing frustration between some decision makers.

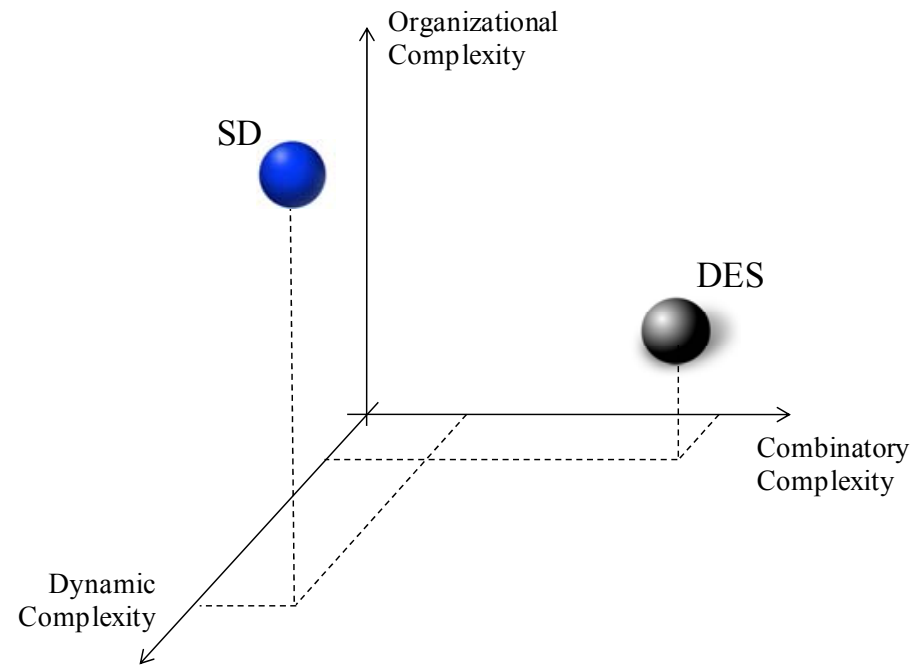

Figure 6: Positioning of the DES and SD methodologies in a tridimensional graphic of complexities (adapted from Lane (2000))

The analysis of Figure 6 (Lane 2000) allows the mapping of the preferential fields of application of the two methodologies in study:

- The great potential of DES is the capacity of representing systems of elevated complexity of details, considering the refinement of data, the scrutiny of the dynamic of events, with little emphasis in the attempt of understanding the relations between the variables, resulting in low capacity of application in systems of elevated dynamic complexity. For the same factors, DES models present a characteristic of greater hegemony in its conception and definition, with less managerial controversy and discussions surrounding its conception and analysis, acting in systems of low organizational complexity. 
- SD operates in contexts of high dynamic complexity and low complexity of details. Elevated degree of aggregation of variables and explicitness of the causal relations between the variables drive the attention to the dynamic behavior of the system. SD models become then tools of discussion and learning for analysis of management strategies, acting in problems with elevated levels of organizational complexity.

If we turn back to Table 1, Table 2 and Table 3, that compile the differences of concept, interpretation, representation and utilization of the two approaches, and try to position the aspirations pertinent to the representation of a logistic system, certainly the selection of the best methodology will be ambiguous, leading either to SD in some aspects, or to DES in others. As an example, in the modeling and simulation process of a port terminal for containers handling, we will be interested in the following issues: initial investment in equipment, policies of investment, maintenance of desired service level; operational results and rates of performance of the terminal, handling incomes, costs of the system (related to delays of ships, trucks and load), and others. The option for the best methodology to represent the system to study the proposed issues with no hesitation and ambiguities is difficult, and is presented in Table 5.

Table 5: Choice of the best methodology to represent the elements of a logistic system

\begin{tabular}{|c|c|c|}
\cline { 2 - 3 } \multicolumn{1}{c|}{} & DES & SD \\
\hline Initial Investment & $\mathbf{X}$ & \\
\hline Investiment Policy & & $\mathbf{X}$ \\
\hline Service Level Evaluation & & $\mathbf{X}$ \\
\hline Operational Results & $\mathbf{X}$ & \\
\hline Performance Rates & $\mathbf{X}$ & \\
\hline Operational Incomes & $\mathbf{X}$ & \\
\hline Costs of the System & $\mathbf{X}$ & \\
\hline Demand Absorption & & $\mathbf{X}$ \\
\hline
\end{tabular}

The potential of the benefits of the jointly utilization of DES and SD is obvious, each applied to the extension of the model for which it is able to work with greater fit. In this context, the proposal of the work gets a boost. It is necessary to explore the potential of the application of the hybrid methodology of simulation, combining the paradigms DES and SD, departing from the comprehension and sharing of its potentialities and weakness. The paradigms DES and SD, in particular as argued by Robinson (2005), Rabelo et al. (2005), and Helal and Rabelo (2004), can complement one another, offering the necessary tools for the construction of new paradigms of simulation with potentiality to reach the requests adapted by the modern, integrated and dynamic world-wide business system. A hybrid methodology of simulation is able to deal with the necessities imposed by the economical world-wide dynamism, to integrate different "visions of world" and to provide efficient answers to everyday more and more complex management and administrative questions.

\section{CONCLUSIONS AND RECOMMENDATIONS}

The main proposal of the work, which corresponds to the generation of a stimulus in the direction of the development of the methodology of hybrid simulation, has been achieved. The preliminary study of each one of the methodologies separately, followed by a deep comparison between both, revealed potentialities, weaknesses and ways of sharing and integration of characteristics, and provided tools for the delineation of a perspective of application and contribution for a common direction.

What guarantees advantage of the hybrid simulation over the discrete or continuous simulation applied separately is not the possibility to work with two models simultaneously, but the capacity of integration between two methodologies, through a process of effective exchange of information and support. Ca- 
pable to handle distinct aspects of the projection of logistics systems, the discrete and continuous models are able to utilize information that the other model is not able to handle. So, the hybrid simulation constitutes an important tool for acting in the current demanding and competitive market of the projection and administration of complex logistics systems.

As a recommendation of extension to the work, the development of a methodology is suggested for the practical integration between two methodologies, followed by tests of exploration of the potentiality of the practical application of the hybrid methodology of simulation.

\section{REFERENCES}

Akkermans, H. A. 1995. "Modeling With Managers: Participative Business Modeling For Effective Strategic Decision-Making." PhD Thesis, Technische Universiteit Eindhoven, Eindhoven.

Borshchev, A., and A. Filippov. 2004. "From System Dynamics and Discrete Event to Practical Agent Based Modeling: Reasons, Techniques, Tools." In Proceedings of the 22nd International Conference of the System Dynamics Society. Oxford, England.

Brailsford S., and N. Hilton. 2001. "A Comparison of Discrete Event Simulation and System Dynamics for Modeling Healthcare Systems." In Proceedings of Operational Research Applied to Health Services (ORAHS) 2000, 18-39. Glasgow, Scotland.

Coyle, R. G. 1985. "Representing Discrete Events in System Dynamics Models: A Theoretical Application to Modeling Coal Production." Journal of Operational Research Society 36(4):307-318.

Forrester, J. W. 1961. Industrial Dynamics. Cambridge, MA: MIT Press.

Graham, A. K. 1980. "Parameter Estimation in System Dynamics Modeling." In Elements of the System Dynamics Method, edited by J. Randers, 143-160. MIT Press: Cambridge, MA.

Helal, M. 2008. "A Hybrid System Dynamics-Discrete Event Simulation Approach to Simulating the Manufacturing Enterprise." PhD Thesis, Department of Industrial Engineering and Management Systems, College of Engineering and Computer Science, University of Central Florida.

Helal, M., and A. Rabelo. 2004. "An Enterprise Simulation Approach to the Development of Dynamic Balanced Scorecards." In Proceedings of American Society of Engineering Management Conference. Alexandria, Virginia, October 20-23.

Helal M., L. Rabelo, J. Sepúlveda, and A. Jones. 2007. "A methodology for Integrating and Synchronizing the System Dynamics and Discrete Event Simulation Paradigms." In Proceedings of the 25th International Conference of the System Dynamics Society. Boston, MA, July 29- August 2.

Jackson, M. C., and P. Keys. 1984. "Towards a System of System Methodologies." Journal of Operational. Research Society 35:473-486.

Lane, D. C. 2000. "You Just Don’t Understand Me.” Working Paper, London School of Economics, Operational Research Group.

Law, A., and W. Kelton. 2000. Simulation Modeling And Analysis. McGrawHill, USA.

Lin, C., T. Baines, J. O'kane, and D. Link. 1998. "A Generic Methodology that Aids the Application of System Dynamics to Manufacturing System Modeling." International Conference on Simulation. York, UK, Sept 30 - October 2.

Mak, H.-Y. 1993. "System Dynamics and Discrete Event Simulation Modeling." Department of Statistical and Mathematical Sciences. London, London School of Economics and Political Science.

Morecroft, J. D. W., and S. Robinson. 2005. "Explaining Puzzling Dynamics: Comparing the Use of System Dynamics and Discrete Event Simulation." In Proceedings of the 23rd International Conference of the System Dynamics Society. Boston, MA, July 17-21.

Rabelo, L., M. Helal, A. Jones, and H. Min. 2005. "Enterprise Simulation: A Hybrid System Approach." International Journal of Computer Integrated Manufacturing 18(6):498-508.

Randers, J. 1980. "Guidelines for Model Conceptualization." In Elements of the System Dynamics Meth$o d$, edited by J. Randers, 117-139. Cambridge, MA: MIT Press. 
Richarson, G. P., and A. L. Pugh. 1981. Introduction to System Dynamics Modeling with DYNAMO. Cambridge, MA: Pegasus Communications.

Robinson, S. 2005. "Discrete-Event Simulation: from the Pioneers to the Present: What Next?" Journal of Operational Research Society 56:619 - 629.

Sterman, J. 2000. Business Dynamics: System Thinking and Modeling for a Complex World. Boston, MA: Irwin/McGraw-Hill.

Sweetser, A. 1999. "A Comparison of System Dynamics (SD) and Discrete Event Simulation (DES)." In Proceedings of 17th International Conference of the System Dynamics Society. Wellington, New Zealand, July 20 - 23.

Tako, A. A., and S. Robinson. 2009a. "Comparing Discrete-Event Simulation and System Dynamics: User's Perception." Journal of the Operational Research 60:296 - 312.

Tako, A. A., and S. Robinson. 2009b. "Comparing Model Development in Discrete-Event Simulation and System Dynamics." In Proceedings of the 2009 Winter Simulation Conference, edited by M. D. Rossetti, R. R. Hill, B. Johansson, A. Dunkin and R. G. Ingalls, 979-991. Piscataway, New Jersey: Institute of Electrical and Electronics Engineers, Inc.

Tesfamarian, D., and B. Lindeberg. 2005. "Aggregate Analysis Of Manufacturing Systems Using System Dynamics And ANP." Computers \& Industrial Engineering 49(1):98-117.

Towill, D., and J. Edghill. 1989. "The Use Of System Dynamics In Manufacturing Systems Engineering." Transactions of the Institute of Measurement and Control 11:208-216.

\section{AUTHOR BIOGRAPHIES}

THIAGO BARROS BRITO completed his undergraduate degree in Industrial Engineering from Escola Politecnica of University of São Paulo (2008) and is currently working on his Master's degree in Logistics Systems Engineering in Escola Politecnica of University of São Paulo. He received specialization in Global Logistics and Supply Chain Management (GC-LOG) at Center for Transportation and Logistics (CTL) in the Massachusetts Institute of Technology (MIT) in 2010. He has experience in the areas of logistics, modeling and simulation, especially in port's environment and management of multimodal transportation systems. His email address is tbbrito@gmail.com.

RUI CARLOS BOTTER completed his undergraduate degree in Naval Engineering from University of São Paulo (1980). He has a Master's degree in Naval and Oceanic Engineering from the University of Sao Paulo (1985), and a PhD degree in Naval and Oceanic Engineering from University of Sao Paulo (1993). He worked as an Associate Professor in Maritime and Fluvial Transportation, Port's and Logistics Planning (2002-2006) and in October of 2006, became Full Professor of Escola Politecnica of the University of Sao Paulo (EPUSP), in the area of Transports and Logistics. Currently he is a researcher of University of Sao Paulo and has a CNPq scholarship for Productivity and Innovative Extension - level 3. He is exPresident of the Pan-American Institute of Naval Engineering in 2006/2007, Vice-Coordinator of the Graduation Program in Logistics Systems Engineering. He has experience in the areas of Naval and Oceanic Engineering, with emphasis in logistics, simulation, maritime transportation, port's systems, acting mainly in the following themes: Modeling of Complex Logistic Systems, Management and Planning of Logistic Systems. His email address is rcbotter@usp.br.

EDSON FELIPE CAPOVILLA TREVISAN completed his undergraduate degree in Naval and Oceanic Engineering from Escola Politecnica of University of São Paulo (2008) and he is currently working on his Master's degree in Logistics Systems Engineering in Escola Politecnica of University of São Paulo. He has experience in the areas of simulation in transports and port's logistics and linear programming. His email address is edsontrevisan21@gmail.com. 